\title{
EL VIDRIO EN LA CONSTRUCCIÓN. SITUACIÓN ACTUAL Y ORIENTACIÓN DE LA I+D*
}

\author{
(GLASS IN CONSTRUCTION. CURRENT SITUATION AND THE R+D ORIENTATION)
}

José Antonio Coto, Director de Investigación y Desarrollo Técnico. Cristalería Española, S. A. ESPAÑA

\section{RESUMEN}

El vidrio, bajo sus diferentes formas y composiciones, constituye uno de los materiales más utilizados en la construcción. Desempeña múltiples funciones: Estética, Confort, Seguridad, ... Aunque se trata de un material muy antiguo, gracias al esfuerzo de $I+D$, está teniendo una importante evolución durante estos últimos años. Se desarrollan nuevas propiedades y funciones mediante modificaciones en su composición, tratamientos de su superficie $o$ asociación con otros productos.

Se recoge, en esta comunicación, un extenso número de nuevos productos y sus procedimientos de obtención, destacando su aplicación y funcionalidad en la construcción. Se da cierta extensión a los diferentes tratamientos de superficie (principalmente, capas delgadas) sobre vidrio plano, por su especial implantación en la construcción actual. Igualmente, se describen los productos compuestos y sus utilizaciones más funcionales.

Los vidrios con propiedades variables a voluntad son objeto de múltiples desarrollos actuales $y$, sin duda, serán de gran aplicación en la construcción en un futuro próximo.

\section{SUMMARY}

Glass, with its different forms and compositions, constitutes one of the most widely used materials in construction. It performs various functions: Aesthetics, Comfort, Security. Although it is an old material, thanks to the effort of the $R+D$ it has undergone significant evolution in the recent years. New properties and functions have been developed through modification of its composition, surface treatment and association with other products.

This article gathers a large number of new products and the procedure for their obtaining, pointing out their application and functionality in construction. There is a certain emphasis on some surface treatments (mainly thin layers) of flat glass, due to its special implantation in modern construction. There is also a description of compound products and their more functional uses.

Glasses with properties varying according to the user's wish are the object of various current developments and will surely have an ample application in the near future.

\section{ACTUALIZACIÓN DE LOS PRODUCTOS DE VIDRIO PLANO EN LA CONSTRUCCIÓN}

Es evidente que un solo producto no puede satisfacer simultáneamente todas las funciones demandadas. Por ello, tanto los esfuerzos de desarrollo de la industria vidriera, como los de investigación en este campo, están orientados, en su mayor parte, a aumentar la funcionalidad del vidrio, a dotarle de nuevas propiedades $y$, en definitiva, a crear productos compuestos que respondan mejor y de forma más completa a las necesidades del utilizador.
Los nuevos productos surgen, a partir del vidrio más convencional, por el efecto de:

\section{- Las modificaciones en su composición.}

\section{- Las transformaciones en su superficie.}

\section{- La asociación con otros productos,}

y, más frecuentemente, por la asociación de varias de estas acciones o la combinación de varios productos.

\footnotetext{
* Extracto del artículo publicado en el n. 221 de nuestra Revista "Materiales de Construcción”, en el primer trimestre de 1991.
} 
TABLA I

Acciones I $+D$ en vidrio plano

\begin{tabular}{|c|c|c|c|}
\hline Actuaciones & \multicolumn{2}{|c|}{ Modificación de propiedades } & Productos derivados \\
\hline \multirow{5}{*}{$\begin{array}{l}\text { En masa } \\
\text { (Comp. vitrificable } \\
\text { y tratamientos) }\end{array}$} & Ópticas & $\begin{array}{l}\text { Transmisión } \\
\text { Color }\end{array}$ & $\begin{array}{l}\text { V. extra-blancos (incoloros) } \\
\text { V. absorbentes (de color) }\end{array}$ \\
\hline & Térmicas & $\begin{array}{l}\text { Choque térmico } \\
\text { Resistencia al fuego }\end{array}$ & V. corta-fuegos \\
\hline & Químicas & Resistencia ataque químico & V. normales \\
\hline & Acústicas & Modificación espesor & V. normales \\
\hline & Mecánicas & $\begin{array}{l}\text { Resistencia a la flexión } \\
\text { Choque y rotura }\end{array}$ & V. templados \\
\hline \multirow{4}{*}{$\begin{array}{l}\text { En superficie } \\
\text { (Tratamientos y capas) }\end{array}$} & Ópticas & $\begin{array}{l}\text { Reflexión luminosa } \\
\text { Reflexión N.I.R. } \\
\text { Foto/electro-cromismo }\end{array}$ & $\begin{array}{l}\text { V. reflectantes } \\
\text { V. de reflexión selectiva } \\
\text { V. antisolares } \\
\text { V. de color y transm. } \\
\text { variables }\end{array}$ \\
\hline & Térmicas & Emisividad (F.I.R.) & V. no emisivos \\
\hline & Químicas & $\begin{array}{l}\text { Desalcalinización } \\
\text { Regulación pH }\end{array}$ & $\begin{array}{l}\text { V. resistentes al } \\
\text { envejecimiento }\end{array}$ \\
\hline & Eléctricas & $\begin{array}{l}\text { Conductividad } \\
\text { Fotovoltaismo }\end{array}$ & $\begin{array}{l}\text { V. auto-calefactores } \\
\text { V. antena } \\
\text { V. fotovoltaico }\end{array}$ \\
\hline \multirow{3}{*}{$\begin{array}{l}\text { Con materiales } \\
\text { compuestos } \\
\text { (Comp. vidrio plástico) }\end{array}$} & Ópticas & Transmisión & V. de color \\
\hline & Mecánicas & $\begin{array}{l}\text { Resistencia al choque y a } \\
\text { la efracción }\end{array}$ & $\begin{array}{l}\text { V. de seguridad (anti robo, } \\
\text { anti-bala) } \\
\text { V. antilacerantes }\end{array}$ \\
\hline & Químicas & Repulsión del agua & V. anti-vaho \\
\hline \multirow{2}{*}{$\begin{array}{l}\text { Unión de vidrios } \\
\text { (Acristalamientos múltiples) }\end{array}$} & Térmicas & $\begin{array}{l}\text { Variación de } \mathrm{K} \\
\text { Aislamiento térmico }\end{array}$ & $\begin{array}{l}\text { V. acristalamientos } \\
\text { múltiples } \\
\text { V. ID. con gases o vacío }\end{array}$ \\
\hline & Acústicas & Atenuación acústica & V. aislantes acústicos \\
\hline
\end{tabular}

En la tabla I se recoge, de forma muy esquemática, una relación de productos derivados de la modificación de ciertas propiedades del vidrio a partir de actuaciones diversas en su masa, en su superficie o mediante combinación entre sí o con otros productos.

\section{NUEVOS VIDRIOS POR MODIFICACIÓN DE LA FORMULACIÓN}

Los vidrios convencionales de silicato tienen una formulación generalmente optimizada en función del proceso de fabricación y de sus usos más comunes.
Son sus propiedades y caracteristicas, que se recuerdan en la tabla II, los que han permitido a este material mantener una progresión continua a medida que los medios de producción lo han permitido.

Basta recordar, por comparación con otros materiales de construcción, como comentario simplificado de la tabla II, que:

- Su propiedad fundamental es la transparencia a la luz ( $88 \%$ de transmisión luminosa para un vidrio incoloro de $10 \mathrm{~mm}$ de espesor) con una Opacidad 


\section{TABLA II}

Propiedades comunes a los productos de vidrio plano

\begin{tabular}{|c|c|}
\hline \multicolumn{2}{|c|}{$\begin{array}{l}\text { A) Propiedades ópticas } \\
\text { (vidrio } 10 \mathrm{~mm} \text { de espesor incoloro) }\end{array}$} \\
\hline $\begin{array}{l}\text { Indice de refracción } \\
\text { Transmisión luminosa } \\
\text { Transmisión energética (") } \\
\text { Factor solar (FS) } \\
\text { (") Transmisión UV. nula hasta } \\
310 \mathrm{~mm} \text {; Transmision I. R. } \\
\text { prácticameme nula a partir de } \\
2000 \mathrm{~nm}\end{array}$ & $\begin{array}{l}n=1,52 \\
88 \% \\
76 \% \\
82\end{array}$ \\
\hline \multicolumn{2}{|c|}{ B) Propiedades mecánicas } \\
\hline $\begin{array}{l}\text { Densidad } \\
\text { Dureza (escala de Mohs) } \\
\text { Resistencia a la abrasión } \\
\text { Elastic. (mod. de Young) } \\
\text { Resist. a la tracción } \\
\text { Resist. a la compresión } \\
\text { Resist. a la flexión }\end{array}$ & $\begin{array}{l}d=2,5 \mathrm{~kg} / \mathrm{dm}^{3} \\
\approx 6,5 \\
16 \mathrm{v} .>\text { q. granito } \\
E=7,3 \cdot 10^{5} \mathrm{~kg} / \mathrm{cm}^{2} \\
400+1.500 \mathrm{~kg} / \mathrm{cm}^{2} \\
>10.000 \mathrm{~kg} / \mathrm{cm}^{2} \\
100+500 \mathrm{~kg} / \mathrm{cm}^{2}\end{array}$ \\
\hline \multicolumn{2}{|c|}{ C) Propiedades térmicas } \\
\hline $\begin{array}{l}\text { Calor especifico } \\
\text { Coef. de dilatación lineal } \\
\text { Conductividad térmica } \\
\text { Resist. al choque térmico } \\
\text { en productos templados }\end{array}$ & $\begin{aligned} \mathrm{C} & =0,19 \mathrm{cal} . / \mathrm{g} \\
\alpha & =8 \times 10^{-6} \\
\lambda & =0,86 \mathrm{kcal} / \mathrm{h} \cdot \mathrm{m}^{2} \cdot{ }^{\circ} \mathrm{C} \\
& \approx 60^{\circ} \mathrm{C} \\
& \approx 240^{\circ} \mathrm{C}\end{aligned}$ \\
\hline \multicolumn{2}{|c|}{ D) Propiedades acústicas } \\
\hline $\begin{array}{l}\text { Indices de atenuación } \\
\text { acústica (vidrio simple de } \\
10 \mathrm{~mm} \text { de espesor) } \\
\text { A ruido de carretera } \\
\text { A ruido rosa } \\
\text { Velocidad del sonido }\end{array}$ & $\begin{array}{l}35 \mathrm{~dB}(\mathrm{~A}) \\
38 \mathrm{~dB}(\mathrm{~A}) \\
5+6 \mathrm{~km} / \mathrm{s}\end{array}$ \\
\hline \multicolumn{2}{|c|}{ E) Propiedades eléctricas } \\
\hline $\begin{array}{l}\text { Conductividad (a } 243^{\circ} \mathrm{C} \text { ) } \\
\left.\text { Resistividad (a } 25^{\circ} \mathrm{C}\right) \\
\text { Constante dieléctrica } \\
\text { Rigidez dieléctrica }\end{array}$ & $\begin{array}{l}K \approx 1 \cdot 10^{-8} \Omega^{-1} \cdot \mathrm{m}^{-1} \\
\rho=5 \cdot 10^{13} \Omega \cdot \mathrm{m} \\
\varepsilon=7,1 \\
40 \mathrm{kV} / \mathrm{cm}\end{array}$ \\
\hline
\end{tabular}

casi total a la radiación UV (de longitud de onda inferior a $310 \mathrm{~nm}$ ) y una reducción en el IR (a partir de $2,5 \mu \mathrm{m}$ y prácticamente nula para $\lambda \geq 5 \mu \mathrm{m}$ ).

- Su Densidad $(2,5)$ es próxima a la del aluminio y un tercio de la del acero.

- La Resistencia a la abrasión es aproximádamente 16 veces superior a la del granito.

- Elasticidad igual a las del aluminio y latón, un tercio de la del acero y triple de la del hormigón.
- Resistencia a la tracción: 10 veces inferior al acero y 20 veces superior al hormigón.

- Resistencia a la compresión similar a la del ace. ro.

- Mala conducción del calor: 400 veces menor que la del cobre.

- Buen aislante acústico y excelente aislante eléctrico.

Modificaciones importantes de algunas de estas características solamente se consiguen mediante cambios sustanciales en la matriz vítrea, dando lugar a nuevas familias de vidrios considerados aun como especiales por su escasa aplicación industrial.

Entre los vidrios no convencionales que progresivamente pueden ir integrándose en la construcción, aunque con una difusión restringida por la dificultad de su fabricación o por su elevado precio, se encuentran los siguientes:

\section{- Vidrios de bajo coeficiente de dilatación}

Los más conocidos, los llamados Borosilicatos, por ser el $\mathrm{B}_{2} \mathrm{O}_{2}$ y el $\mathrm{SiO}_{2}$ los óxidos que comparten el papel de formadores de la red vítrea, contienen muy bajas cantidades de fundentes $\left(\mathrm{Na}_{2} \mathrm{O}\right)$ y relativamente elevadas de estabilizantes $\left(\mathrm{Al}_{2} \mathrm{O}_{3}\right)$. Se consiguen así vidrios fusibles (aunque a temperaturas algo más elevadas que los convencionales), muy estables químicamente y con bajos coeficientes de dilatación, lo que equivale a buena resistencia a los choques térmicos.

Esta última propiedad es la que ha extendido la utilización de estos vidrios en usos de laboratorio y domésticos. En la Construcción se proponen como solución de tabiques o mamparas transparentes para uso como corta-fuegos.

\section{- Los vidrios cerámicos o vitro-cerámicos}

En los que se asocian las propiedades del vidrio y las de las cerámicas mediante la generación de núcleos o fases cristalinas dentro de la fase vítrea.

En general, después de la fusión de la composición conteniendo pequeñas cantidades de agentes nucleantes $\left(\mathrm{TiO}_{2}, \mathrm{P}_{2} \mathrm{O}_{5}, \mathrm{ZrO}_{2}, \ldots\right)$ y de la conformación del vidrio, se somete a éste a un ciclo térmico que facilite la formación de núcleos y el crecimiento de cristales hasta el tamaño deseado (microcristales).

Son bastante conocidos algunos de estos productos vitrocerámicos en usos domésticos o de laboratorio y en aplicaciones muy especiales (p. ej. grandes lentes de telescopios con vitrocerámicos transparentes de coeficiente de dilatación nulo). 


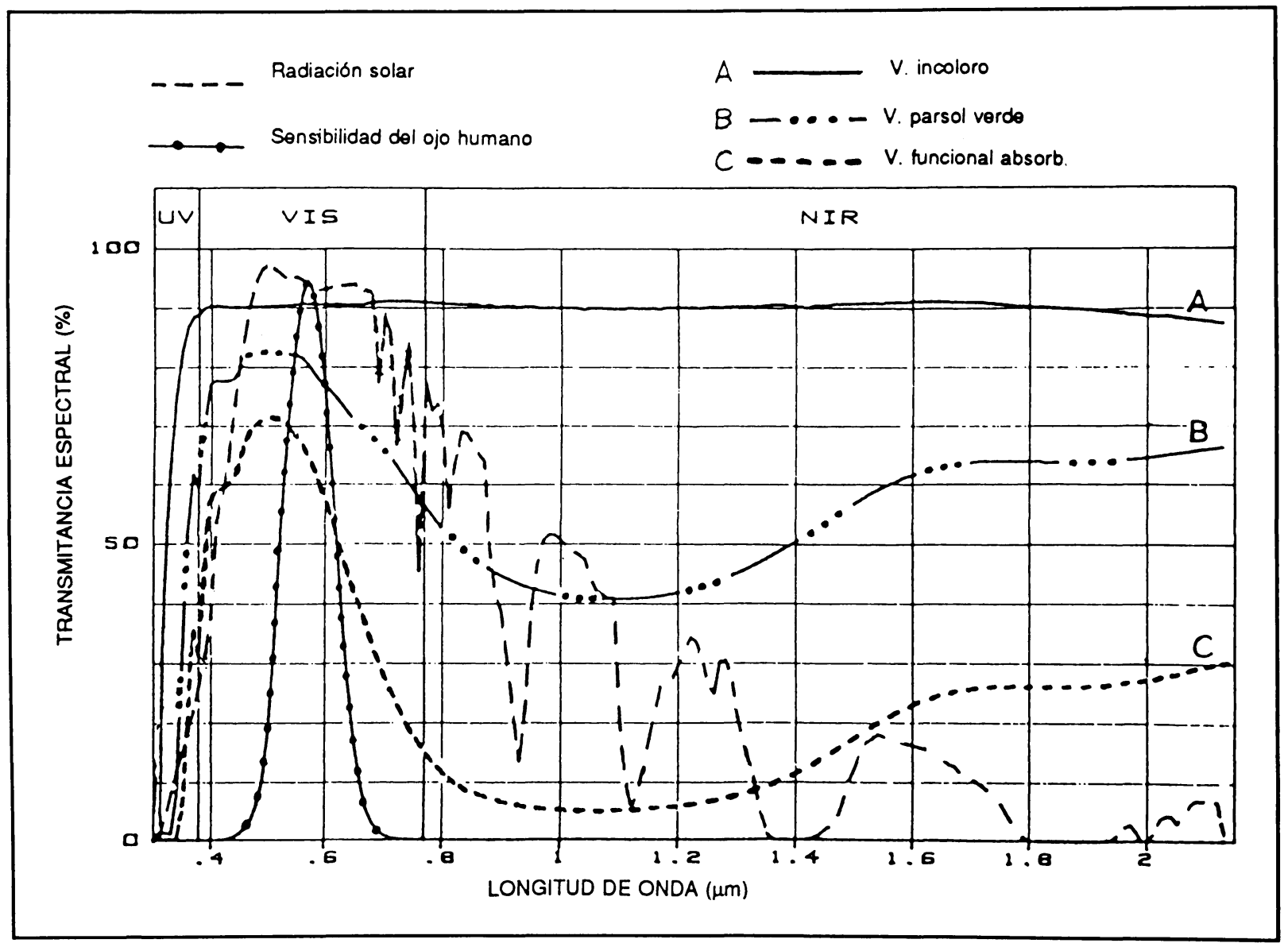

Fig. 1

Su aplicación a la contrucción se hará también en usos muy particulares donde sea necesario aprovechar su excelente resistencia térmica y mecánica.

\section{- Vidrios para absorción de radiaciones}

Están ligados casi exclusivamente a la construcción en la industria nuclear. Se utilizan para las ventanas de las células con fuentes radioactivas donde es necesaria la vigilancia y la manipulación a distancia.

Dado que el poder de absorción de la radiación $\gamma$ es función de la masa del material interpuesto, estos vidrios especiales, obtenidos con contenidos elevados de $\mathrm{PbO}$, tienen densidades del orden de 5 (doble de la de los vidrios comunes) y se utilizan en espesores elevados. Un acristalamiento para este uso, compuesto por varias placas de vidrio, puede llegar a tener un espesor total o superior a un metro.

En los vidrios convencionales las modificaciones de su composición se hacen, en general, para ajustar los parámetros influyentes en la conformación a las exigencias del proceso de fabricación. Pero también se hacen variaciones de componentes, principalmente los llamados "colorantes", para alterar voluntariamente las características espectrofotométricas del vidrio y ajustarlas a la funcionalidad que se desea obtener.

Son principalmente los iones de los metales de transición contenidos en los vidrios los responsables de ciertas bandas de absorción a determinadas longitudes de onda. Aprovechando este efecto, mediante la adición de ciertos óxidos metálicos $\left(\mathrm{Fe}_{2} \mathrm{O}_{3}, \mathrm{CoO}, \mathrm{Cr}_{2} \mathrm{O}_{3}\right.$, $\mathrm{NiO}$, etc.), pueden modificarse a voluntad tanto su co. lor como su transmitancia lo que permite actuar sobre la funcionalidad tanto en el aspecto "estético" como en el de "confort térmico y visual". Las posibilidades teóricas de vidrios diferentes (desde el incoloro al opa. co por máxima absorción) son ilimitadas. Solamente, la pureza de las materias primas y el propio proceso de fabricación limitan estas posibilidades. 


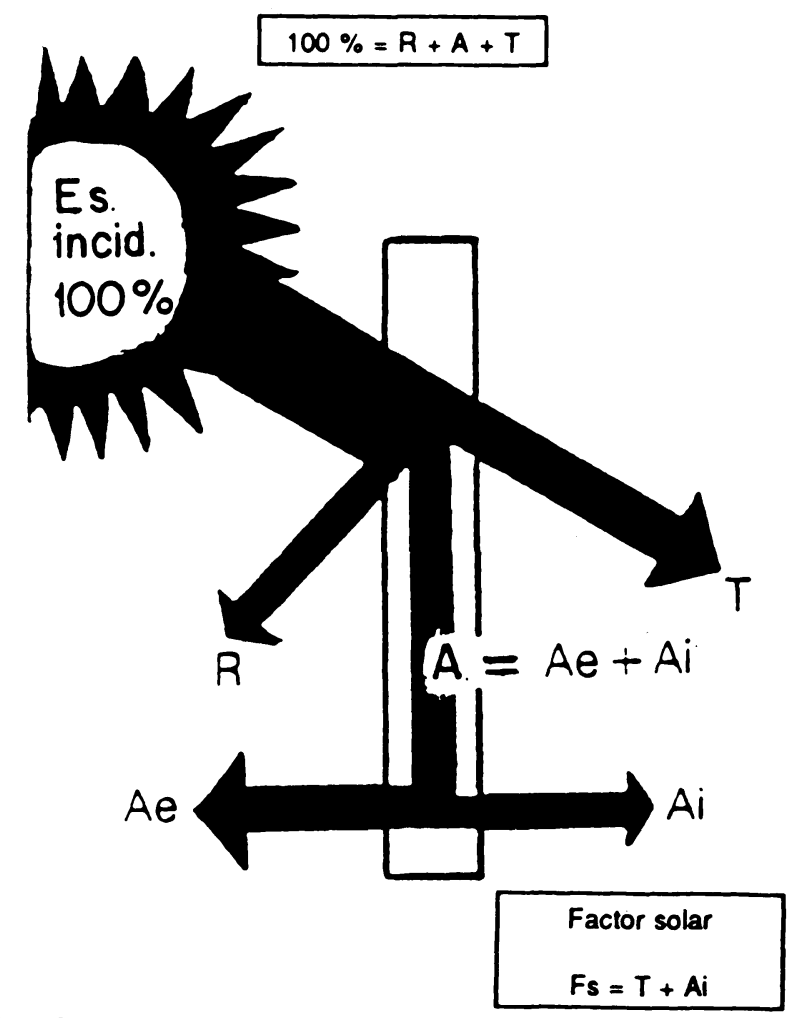

$R=$ Factor de reflexión

$T=$ Factor de transmisión

$A e=$ Absorción reenviada al exterior

$A i$ = Absorción reenviada al interior

Fig. 2

Como ejemplo de vidrios de este tipo, con aplicaciones diversas en la construcción, pueden citarse los vidrios incoloros, los vidrios de color y absorbentes (tipo "PARSOL') y los vidrios funcionales muy absorben. tes. En la Fig. 1 se representan las curvas de transmitancia espectral de tres de estos vidrios.

Para valorar la utilidad de este tipo de vidrios es preciso recordar los dos componentes asociados:

- El Sol, como fuente de radiaciones que proporcionan luz y calor. Al nivel de la tierra, estas radiaciones se extienden entre longitudes de onda de 0,3 a 2,2 $\mu \mathrm{m}$. (En la Fig. 1 se representa, como referencia, la curva de distribución espectral establecida por Parry Moon).

La distribución aproximada de la energía es: $5 \%$ en la región UV $(\lambda<0,38 \mu \mathrm{m}) ; 50 \%$ en la región visi- ble (de 0,38 a 0,78 $\mu \mathrm{m}$ ) y $45 \%$ en el IR (a partir de 0,78 $\mu \mathrm{m})$.

- La respuesta del ojo humano a una radiación de $\lambda$ dada. Se representa también el la Fig. 1 mediante la curva de sensibilidad relativa. La eficacia del ojo es máxima para $\lambda=0,55 \mu \mathrm{m}$ (zona de verdes-amarillos).

La sensación luminosa (respuesta del ojo) recibida a través del acristalamiento corresponde a la energía recibida ponderada por el factor de transmisión del vidrio y el factor de eficacia del ojo.

La cantidad de energía que atraviesa el acristalamiento y se transforma en calor está definida por el factor solar (Fig. 2) que corresponde a la suma de la energía solar transmitida directamente a través del vidrio $(T)$ y la parte de la absorbida (A) por él e irradiada hacia el interior ( $\mathrm{Ai}$ ) en relación con el total de energía incidente. 
TABLA III

Características luminosas y energéticas

\begin{tabular}{|c|c|c|c|c|c|c|c|}
\hline \multirow[t]{2}{*}{ Producto } & \multirow{2}{*}{$\begin{array}{l}\text { Espesor } \\
\text { mm }\end{array}$} & \multicolumn{2}{|c|}{$\begin{array}{l}\text { Factores luminosos } \\
\text { (luz natural) } \\
380-780 \mathrm{~nm}\end{array}$} & \multicolumn{3}{|c|}{$\begin{array}{c}\text { Factores energéticos (energía solar) } \\
\qquad 300-2.200 \mathrm{~nm}\end{array}$} & \multirow{2}{*}{$\begin{array}{l}\text { Factor } \\
\text { solar }\end{array}$} \\
\hline & & $\mathbf{R}_{\mathbf{L}}$ & $T_{L}$ & $\mathbf{R}$ & A & $\mathbf{T}$ & \\
\hline \multicolumn{8}{|c|}{ Lunas CRISTANNOLA no absorbentes } \\
\hline PLANILUX & $\begin{array}{c}2 \\
3 \\
4 \\
5 \\
6 \\
8 \\
10 \\
15 \\
19\end{array}$ & $\begin{array}{l}0.08 \\
0.08 \\
0.08 \\
0.08 \\
0.08 \\
0.08 \\
0.08 \\
0.08 \\
0.08\end{array}$ & $\begin{array}{l}0.92 \\
0.91 \\
0.90 \\
0.90 \\
0.89 \\
0.89 \\
0.88 \\
0.83 \\
0.81\end{array}$ & $\begin{array}{l}0.07 \\
0.07 \\
0.07 \\
0.07 \\
0.07 \\
0.07 \\
0.07 \\
0.07 \\
0.07\end{array}$ & $\begin{array}{l}0.06 \\
0.06 \\
0.08 \\
0.09 \\
0.11 \\
0.15 \\
0.17 \\
0.21 \\
0.23\end{array}$ & $\begin{array}{l}0.87 \\
0.87 \\
0.85 \\
0.84 \\
0.82 \\
0.78 \\
0.76 \\
0.72 \\
0.70\end{array}$ & $\begin{array}{l}0.88 \\
0.88 \\
0.88 \\
0.87 \\
0.85 \\
0.82 \\
0.80 \\
0.79 \\
0.79\end{array}$ \\
\hline PINK-ROSA & $\begin{array}{c}4 \\
5 \\
6 \\
10\end{array}$ & $\begin{array}{l}0.06 \\
0.06 \\
0.06 \\
0.06\end{array}$ & $\begin{array}{l}0.75 \\
0.73 \\
0.70 \\
0.58\end{array}$ & $\begin{array}{l}0.06 \\
0.06 \\
0.06 \\
0.06\end{array}$ & $\begin{array}{l}0.17 \\
0.19 \\
0.22 \\
0.32\end{array}$ & $\begin{array}{l}0.77 \\
0.75 \\
0.72 \\
0.62\end{array}$ & $\begin{array}{l}0.81 \\
0.80 \\
0.78 \\
0.70\end{array}$ \\
\hline \multicolumn{8}{|c|}{ Lunas CRISTAÑOLA absorbentes } \\
\hline $\begin{array}{l}\text { PARSOL } \\
\text { gris }\end{array}$ & $\begin{array}{c}4 \\
5 \\
6 \\
10\end{array}$ & $\begin{array}{l}0.05 \\
0.05 \\
0.05 \\
0.05\end{array}$ & $\begin{array}{l}0.56 \\
0.50 \\
0.44 \\
0.27\end{array}$ & $\begin{array}{l}0.05 \\
0.05 \\
0.05 \\
0.05\end{array}$ & $\begin{array}{l}0.35 \\
0.41 \\
0.46 \\
0.62\end{array}$ & $\begin{array}{l}0.60 \\
0.54 \\
0.49 \\
0.33\end{array}$ & $\begin{array}{l}0.69 \\
0.64 \\
0.60 \\
0.48\end{array}$ \\
\hline $\begin{array}{l}\text { PARSOL } \\
\text { bronce }\end{array}$ & $\begin{array}{c}4 \\
5 \\
6 \\
10\end{array}$ & $\begin{array}{l}0.05 \\
0.05 \\
0.05 \\
0.05\end{array}$ & $\begin{array}{l}0.61 \\
0.55 \\
0.50 \\
0.33\end{array}$ & $\begin{array}{l}0.05 \\
0.05 \\
0.05 \\
0.05\end{array}$ & $\begin{array}{l}0.36 \\
0.42 \\
0.48 \\
0.64\end{array}$ & $\begin{array}{l}0.59 \\
0.53 \\
0.47 \\
0.31\end{array}$ & $\begin{array}{l}0.68 \\
0.63 \\
0.59 \\
0.47\end{array}$ \\
\hline $\begin{array}{l}\text { PARSOL } \\
\text { verde }\end{array}$ & $\begin{array}{c}4 \\
5 \\
6 \\
10\end{array}$ & $\begin{array}{l}0.07 \\
0.07 \\
0.07 \\
0.07\end{array}$ & $\begin{array}{l}0.81 \\
0.77 \\
0.74 \\
0.64\end{array}$ & $\begin{array}{l}0.05 \\
0.05 \\
0.05 \\
0.05\end{array}$ & $\begin{array}{l}0.40 \\
0.46 \\
0.51 \\
0.63\end{array}$ & $\begin{array}{l}0.55 \\
0.49 \\
0.44 \\
0.32\end{array}$ & $\begin{array}{l}0.65 \\
0.61 \\
0.57 \\
0.48\end{array}$ \\
\hline
\end{tabular}

Las características particulares y empleo de los tres vidrios tipo, cuyas curvas de transmisión se representan en la Fig. 1 son:

\section{A) Vidrios incoloros tipo "PLANILUX"}

Son muy frecuentemente utilizados en la construcción. Son vidrios de elevada transmisión luminosa y energética. (Para e $<10 \mathrm{~mm}$, TL $90 \%$ y FS $>0,8$ ).

Son vidrios adecuados para facilitar los aportes luminosos y energéticos solares.

Como vidrio especial, dentro de este grupo, está el extra-blanco, cuya característica principal es su extre- mada transparencia y pureza. Su utilización más conocida en la Pirámide del Museo de Louvre ha permitido el empleo de placas de $20 \mathrm{~mm}$ de espesor $(10+10)$ no alterando los matices cromáticos del entorno y dando una apariencia de ligereza a la construcción. Estos vidrios, con una absorción energética solamente del orden del $1 \%$, se utilizan también en equipos de recuperación y captación de la energía solar.

\section{B) Vidrios absorbentes "PARSOL"}

Son vidrios muy utilizados en la construcción dentro de la gama de protección solar. Son vidrios de color. 
TABLA IV

Tratamientos de superficie

\begin{tabular}{|l|l|}
\hline \multirow{2}{*}{ Por extracción de materia } & Abrasión/mateado \\
\cline { 2 - 2 } & Ataque químico \\
\hline \multirow{2}{*}{$\begin{array}{l}\text { Por modificación física } \\
\text { estructura }\end{array}$} & Temple \\
\hline \multirow{2}{*}{$\begin{array}{l}\text { Por modificación de } \\
\text { composición }\end{array}$} & $\begin{array}{l}\text { Efecto eléctrico/ } \\
\text { /desalcalinización }\end{array}$ \\
\cline { 2 - 2 } & $\begin{array}{l}\text { Desvitrificación/ } \\
\text { /ataque químico }\end{array}$ \\
\hline Por depósito de materia & Cementación \\
\cline { 2 - 2 } & $\begin{array}{l}\text { Intercambio iónico/ } \\
\text { /temple químico }\end{array}$ \\
\hline
\end{tabular}

En éstos, una parte importante de la radiación solar incidente ( $~ 50 \%$ para $6 \mathrm{~mm}$ de espesor), es absorbida por el vidrio y posteriormente remitida en forma de IR, tanto hacia el exterior como al interior, en proporciones que dependen de las velocidades del aire y de las temperaturas.

Los valores de $T_{L}$ y $F S$ (muy variables con el espesor) se indican en la tabla $\mathrm{V}$.

\section{C) Vidrios funcionales muy absorbentes}

El vidrio $C$ (curva de transmisión en la Fig. 1) es un caso particular de los vidrios de color "en masa". Utili- zando adecuadamente los componentes colorantes y las condiciones de fusión, se llega a un vidrio que manteniendo un valor de Transmisión Luminosa suficientemente elevado $\left(T_{L}>60 \%\right)$ tiene un valor relativamente bajo de Transmisión Energética $\left(T_{E} \sim 30 \%\right)$ debido a la fuerte banda de absorción que presenta en la zona del infrarrojo solar.

Son vidrios de color con una buena funcionalidad res. pecto al confort climático y la protección solar.

Con los tipos de vidrios mostrados, obtenidos por modificaciones pequeñas en la composición de un vidrio "base" y el adecuado ajuste de las condiciones de elaboración, puede hacerse una regulación selectiva de la radiación solar según el vidrio elegido. Mantener o atenuar la Transmisión Luminosa, la sensación de color, limitar aportaciones caloríficas al interior del edificio, son algunas de las posibilidades que ofrece la elección del vidrio adecuado.

Cualquiera de estos vidrios se utiliza también como substrato para otras transformaciones (Acristalamientos aislantes, de seguridad, con capas metálicas reflectantes, etc., etc.) que pueden complementar o mejorar su funcionalidad.

\section{VIDRIOS CON TRATAMIENTOS SUPERFICIALES}

Las modificaciones de la superficie del vidrio han permitido ampliar la gama de productos y prestaciones disponibles a partir de un único producto de base. Esta mayor disponibilidad y enriquecimiento de sus aportaciones, tanto estéticas como tecnológicas, han tenido un papel transcendente en la evolución de la cons. trucción de edificios durante las últimas décadas. Al igual que en el vidrio, en la construcción la superficie (las fachadas) ha ganado importancia.

Son numerosos los tratamientos de superficie conocidos y empleados desde hace largo tiempo. En la tabla IV se recogen algunos de los más importantes, subrayando el último de ellos: "Depósitos de capa fina", que es, sin duda, el de máxima evolución en estos últimos años y sobre todo en el que se orientan numerosos trabajos actuales de investigación. Son muchos los nuevos productos que están surgiendo de las diferentes vías abordadas en este campo. Se tratarán con algún detalle en un apartado posterior.

Algunos de los productos, más utilizados en la construcción, obtenidos a partir de tratamientos de superficie (exceptuadas las capas finas) son:

\section{- Vidrios planos templados}

Frecuentemente, los acristalamientos de vidrio están sometidos a esfuerzos de flexión que se traducen en 


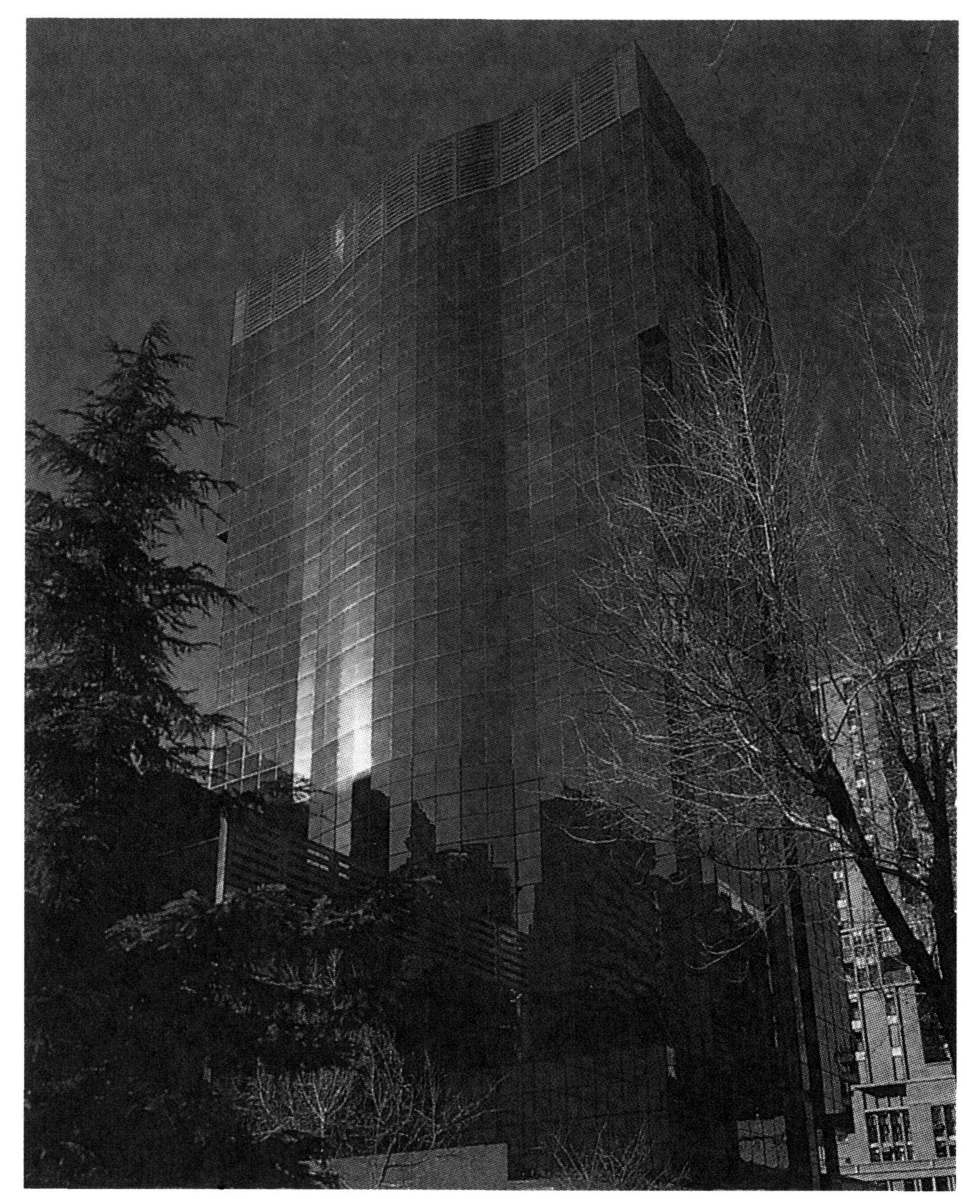

tensiones de compresión en una de sus caras y de tracción en la cara opuesta. Como ya es conocido, el vidrio tiene una buena resistencia a la compresión (similar a la del acero) y una resistencia peor a la tracción (10 veces inferior a la del acero). Como además es un material perfectamente elástico, cuando se le somete a una tensión de tracción suficientemente grande puede, en función del estado de superficie y de sus bordes, producirse la rotura sin dar lugar a una deformación previa.

Para aumentar la resistencia a la flexión hay varios procedimientos que consisten en poner sus dos caras en una fuerte compresión que compense las tracciones que se pueden originar durante su uso:

\section{- Temple térmico}

Se calienta el vidrio, previamente cortado a la dimensión de utilización, hasta temperaturas del orden de los $700^{\circ} \mathrm{C}$ y se enfrían bruscamente las superficies de la hoja. Éstas se "fijan" antes que la parte central. Cuando ésta se enfría, se contrae y somete a una compresión permanente a una fina capa de las superficies.

Se aumenta asi considerablemente la resistencia a la flexión (5 a 10 veces superior al vidrio no templado). (C) Consejo Superior de Investigaciones Científicas Licencia Creative Commons 3.0 España (by-nc)
Además tiene otros efectos inducidos como: Un incremento notable de la resistencia al choque térmico y una fragmentación en pequeños trozos que hacen mucho menos peligrosas las roturas.

Su uso, muy extendido hace algunos años en fachadas, puertas interiores, etc., está siendo desplazado por los productos compuestos (tipo STADIP) de máxima seguridad.

Este procedimiento de refuerzo se utiliza por prescripción en aquellos vidrios que por su elevada absorción energética pueden tener riesgos de rotura por choque térmico.

\section{- Temple químico}

Mediante el intercambio iónico en la superficie (sustitución de iones de Sodio por iones más grandes de Potasio), con un tratamiento de inmersión del vidrio en sales fundidas a determinada temperatura, se consigue también crear esfuerzos de compresión en las caras del vidrio.

El proceso es más complejo que el anterior y los tiempos de tratamiento mucho más largos para obtener espesores en compresión suficientes (> $50 \mu \mathrm{m}$ ). http://informesdelaconstruccion.revistas.csic.es 
TABLA V

Funcionalidad del vidrio con capas

\begin{tabular}{|c|c|c|c|}
\hline \multicolumn{2}{|c|}{ Región espectral } & $\begin{array}{c}\text { Propiedad modificada } \\
\text { por la capa }\end{array}$ & $\begin{array}{c}\text { Función del vidrio } \\
\text { con capa }\end{array}$ \\
\hline \multirow{5}{*}{ Visible $(0,42$ a $0,72 \mu \mathrm{m})$} & & \multirow{2}{*}{ Color } & Estética \\
\hline & & & $\begin{array}{l}\text { Sustitución de la coloración } \\
\text { del vidrio en masa }\end{array}$ \\
\hline & & \multirow{2}{*}{ Reflexión aumentada } & $\begin{array}{l}\text { Confort en verano } \\
\text { (construcción) }\end{array}$ \\
\hline & & & $\begin{array}{l}\text { Economias de } \\
\text { climatización }\end{array}$ \\
\hline & & Reflexión disminuida & Estética (anti-reflejo) \\
\hline \multirow{3}{*}{ Solar $(0.3$ a $2.2 \mu \mathrm{m})$} & \multirow{2}{*}{$\begin{array}{l}\text { Infrarrojo solar } \\
(0,7 \text { a } 2,2 \mu \mathrm{m})\end{array}$} & \multirow{2}{*}{ Reflexión aumentada } & $\begin{array}{l}\text { Confort en verano } \\
\text { (construcción, automóvil) }\end{array}$ \\
\hline & & & $\begin{array}{l}\text { Economias de } \\
\text { climatización }\end{array}$ \\
\hline & $\begin{array}{l}\text { Ultravioleta } \\
(0,3 \text { a } 0,42 \mu \mathrm{m})\end{array}$ & Transmisión disminuida & $\begin{array}{l}\text { Antidecoloración } \\
\text { (protección de los objetos } \\
\text { expuestos en vitrinas, } \\
\text { obras de arte...) }\end{array}$ \\
\hline \multicolumn{2}{|c|}{ Infrarrojo lejano (centrado a unas $13,5 \mu \mathrm{m}$ ) } & Reflexión aumentada & Economias de calefacción \\
\hline
\end{tabular}

Las compresiones que se consiguen son muy elevadas llegando los vidrios a resistencias a la flexión del orden de los $10.000 \mathrm{~kg} / \mathrm{cm}^{2}$.

Se utilizan estos vidrios en aplicaciones muy especiales y cuando se desea reforzar vidrios muy delgados.

\section{VIDRIOS PLANOS CON CAPAS SUPERFICIALES}

Durante los últimos 10 años se ha desarrollado de forma espectacular la aplicación de capas sobre el vidrio. Teniendo en cuenta los diferentes procedimientos de aplicación, los diversos componentes de la capa, los numerosos substratos posibles y combinaciones de éstos, el número de productos que ya existe sobre el mercado, y los que continuamente aparecen fruto de las investigaciones y desarrollos en curso, es tan importante y $\tan$ extendido su uso, que puede decirse que con las capas se ha iniciado una nueva e innovadora etapa del vidrio en la construcción.

Volviendo al esquema de la tabla II, estos vidrios cubren de forma selectiva la funcionalidad para la que han sido diseñados:

- Contribuyen de forma total a la estética y diseño del edificio. Asociados a los muros-cortina, sistemas
Structural Glazing, etc., dando lugar a las fachadas todo-vidrio, más o menos reflectantes y con colores diversos, han contribuido a realzar los efectos de volúmenes y superficies a la vez que la singularidad de cada edificio, aspectos fundamentales en la arquitectura.

- Resuelven directamente los problemas de confort térmico regulando a la vez y selectivamente la transmisión luminosa y los aportes (o en otros casos pérdidas) energéticas a través del acristalamiento.

- Aportan nuevas funciones al vidrio y son base de productos más complejos: V. electrocrómicos; V. con cristales líquidos; etc.

De forma general, las capas aplicadas sobre un substrato de vidrio convencional pueden aportar modificaciones en sus propiedades:

\section{- Espectrofotométricas:}

- Transmisión luminosa/Transmisión energétical Factor solar.

- Color (por transmisión y por reflexión). 
- Reflexión selectiva $\left(R_{L} / R_{E} / R_{\mathbb{R}}\right)$.

\section{- Eléctricas:}

- Conductividad de superficies/Fotovoltaismo.

- Térmicas:

- Variación de FS (consecuencia de las anteriores).

- Transmisión de calor (modificación de la emisividad).

La modificación de las propiedades ópticas del vidrio en las regiones espectrales definidas por la radiación solar y por el IR lejano (característica de las emisiones de materiales y calefacción del interior de los edificios), define las principales funciones aportadas por las capas finas. De manera muy esquemática y simplificada, en la tabla $V$, se resumen las propiedades modificadas y la funcionalidad obtenida.

Se consigue así una extensa gama de productos:

- Semi-reflectantes; espejos; antirreflectantes; de baja emisividad; de superficie conductora; etc.

Ante los numerosos productos existentes con funciones parecidas, solamente el proceso de depósito y los materiales que se depositan (características de cada fabricante) definen y diferencian unas capas de otras.

A continuación se hace una breve descripción de los diferentes procedimienos utilizados acompañado de algún ejemplo de los productos obtenidos y sus usos más frecuentes:

\section{- Depósitos químicos}

Por reacción química sobre el substrato. Se obtienen capas metálicas, generalmente poco resistentes por su débil adhesión al soporte.

Es un procedimiento antiguo cuyo empleo actual está prácticamente limitado a la fabricación de "ESPEJOS" (Dos capas metálicas de Ag y Cu protegidas por pinturas orgánicas). Su uso es bien conocido, sobre todo, en decoración e interiores.

\section{- Depósitos por pirólisis}

Se trata, en cualquier caso, de una descomposición a elevadas temperaturas (prox. a $600^{\circ} \mathrm{C}$ ) de componentes químicos que reaccionan dando lugar a nuevos compuestos que se integran en forma de capa fina y homogénea sobre la superficie del vidrio.
La ventaja de estos depósitos es que al incorporarse sobre el vidrio a elevadas temperaturas su adherencia es muy buena (por reacciones entre el propio vidrio y los componentes constitutivos de la capa en las superficies límite de contacto). Además de esa importante ventaja, que mejora la resistencia mecánica de las capas, normalmente, estos depósitos se realizan en continuo, directamente sobre la línea de fabricación del vidrio, con elevadas cadencias de producción y relativos bajos costes.

En los depósitos por pirólisis se establece una diferencia en función del estado de los componentes aportados:

\section{- Pirólisis en fase vapor (CVD)}

Los componentes de pirólisis, originalmente en estado gaseoso o gasificados previamente, se hacen entrar en contacto con la superficie caliente del vidrio mediante un dispositivo especial.

El único problema de este procedimiento es que la velocidad de formación de la capa es pequeña y esto limita la velocidad de circulación del vidrio (para fabricación en línea continua).

Un ejemplo característico son los vidrios tipo "REFLECTASOL":

El componente principal utilizado es gas Silano $\left(\mathrm{SiH}_{4}\right)$, que se descompone por encima de los $400^{\circ} \mathrm{C}$, sin la presencia de oxígeno, dejando libre el Silicio elemental que se deposita sobre el vidrio formando la capa.

Se aprovechan así las condiciones favorables del baño "Float" (de la fabricación de vidrio plano): temperaturas de aproximadamente $600^{\circ} \mathrm{C}$; atmósfera reductora; condiciones de marcha bien controladas; etc.

Es un producto anti-solar (tiene una alta reflexión luminosa y energética solar) con especiales aplicaciones en climas cálidos y lugares muy soleados. Su factor solar es próximo al $50 \%$ (tabla VI).

Esta capa resiste bien la manufactura, temple, ensamblado en dobles acristalamientos laminares, etc.

\section{- Pirólisis en fase líquida}

Se trata de proyectar una suspensión o solución, sobre el vidrio caliente, con un portador en estado líquido.

Los precursores más frecuentes son las soluciones en un disolvente adecuado de compuestos organometálicos de $\mathrm{Cr}, \mathrm{Co}, \mathrm{Ni}, \mathrm{Fe}, . .$. 
TABLA VI

\begin{tabular}{|c|c|c|c|c|c|c|}
\hline \multirow{2}{*}{ Producto } & \multirow{2}{*}{$\begin{array}{c}\text { Espesor } \\
(\mathrm{mm}) .\end{array}$} & \multicolumn{2}{|c|}{$\begin{array}{l}\text { Factores luminosos } \\
\text { (Iuz natural) }\end{array}$} & \multicolumn{2}{|c|}{$\begin{array}{l}\text { Factores energéticos } \\
\text { (energía solar) }\end{array}$} & \multirow{2}{*}{$\begin{array}{l}\text { Factor } \\
\text { solar }\end{array}$} \\
\hline & & Reflexión & Tranmisión & Reflexión & Tranmisión & \\
\hline REFLECTASOL & 6 & 0,51 & 0,33 & 0,36 & 0,45 & 0,51 \\
\hline CLIMALIT (") & 18 & 0.51 & 0,29 & 0,38 & 0,34 & 0,43 \\
\hline PLANILUX & 6 & 0,08 & 0,89 & 0,07 & 0,82 & 0,85 \\
\hline
\end{tabular}

(*) Acristalamiento aislante CLIMALIT.-Composición: REFLECTASOL $6 \mathrm{~mm}+$ cámara de aire $6 \mathrm{~mm}+$ PLANILUX $4 \mathrm{~mm}$.

Se aplican con un sistema de proyectores directamente sobre la hoja de vidrio caliente en la propia línea de fabricación. La descomposición de estos compuestos deja depositados sobre el vidrio los diferentes óxidos metálicos responsables de las propiedades de la capa.

Este procedimiento proporciona capas de muy buena resistencia química y mecánica, y suficientemente duras y estables para permitir tratamientos posteriores: temple, curvado, esmaltado, etc.

Se producen asi los vidrios tipo "ANTELIO" también de características anti-solares $\left(R_{L}=0,34, R_{E}=0,28\right.$ y $\mathrm{FS}=55 \%$ ).

Tanto en fase vapor como líquida se pueden fabricar también capas de otras características, como las electroconductoras (p. ej.).

\section{- Pirólisis en fase sólida}

Procedimiento y tecnología desarrollada por SAINT GOBAIN para la fabricación de capa "EKO". Consiste en proyectar sobre el vidrio caliente, mediante un sistema de distribución lineal, un flujo gaseoso portador de los granos finamente divididos (50 A) del compuesto reactivo. Por descomposición pirolítica se forma sobre el vidrio una capa de un semi-conductor transparente $\left(\mathrm{SnO}_{2}\right)$ dopado con fluor $(\mathrm{F})$.

Con la introducción del dopante (F) se baja la resistividad del $\mathrm{SnO}_{2}$. El elevado contenido de portadores de carga asociado a su gran movilidad hace que estas capas presenten una conductividad metálica lo que equivale a una elevada reflexión en el infrarrojo. Son capas de baja emisividad.

La CAPA "EKO" se obtiene en la misma línea de fabricación del vidrio soporte, es decir, en anchura de 3,2 m, sobre vidrio de varios espesores y en marcha continua (a velocidad de hasta $20 \mathrm{~m} / \mathrm{min}$ ).

Es una capa transparente. Deja pasar la mayor parte de la energía solar (tiene un Factor Solar de $\sim 74 \%$ ya instalada en un doble acristalamiento). Presenta un color ligeramente azul por reflexión desde el exterior y es neutro por transmisión desde el interior. Su propiedad más importante es reflejar la radiación infrarroja emitida desde el interior del edificio, es decir, reducir las pérdidas caloríficas por el acristalamiento (el coef. de transmisión térmica $\mathrm{K}$ de un D.A. se reduce en un $30 \%$ ) y disminuir el efecto de "pared fría". Es un producto dirigido al confort térmico y a las economías de energia.

Es una capa de muy buena resistencia a la abrasión, a la corrosión del ambiente y soporta perfectamente el envejecimiento. En España se comercializa formando parte de un doble acristalamiento (el CLIMALIT PLUS)

\section{- Depósitos superficiales bajo vacio}

Este tipo de capas finas, con un importante desarrollo actual, están marcando una nueva época en el arte de construir. La extensa gama de productos realizable con estas tecnologías permite personalizar cada edificio con la combinación elegida de colores y reflexiones, a la vez que se le dota del confort luminoso y térmico deseado. La combinación con otros productos de vidrio puede añadirle el resto de funciones como la seguridad.

De forma general, estos procedimientos de obtención de capas consisten en:

- Transformar el material a depositar en vapor dentro de una cámara de vacio.

- Orientar y transferir este vapor al vidrio. 


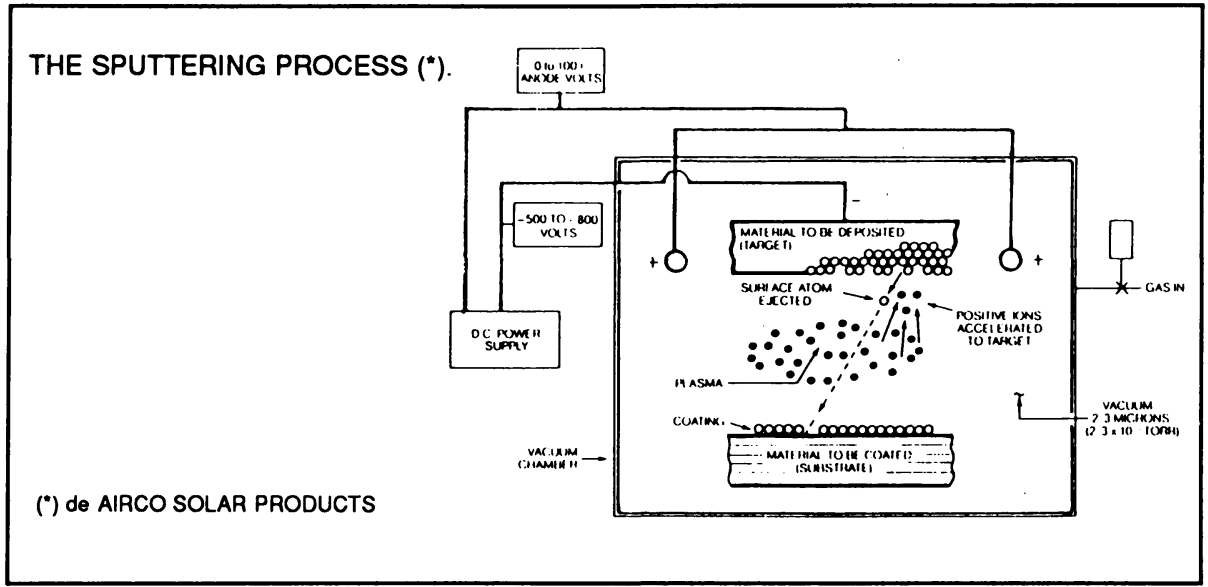

Fig. 3

- Condensarle sobre la superficie del vidrio formando una capa final.

Son especialmente adecuados para depositar metales y aleaciones de éstos, pero con los desarrollos más modernos de esta tecnología también se pueden depositar óxidos, carburos, nitruros, etc. y formar diversos apilamientos de capas.

El vapor del material a depositar se produce por dos técnicas diferentes: evaporización y pulverización.

- Evaporización. Mediante el calentamiento del material a depositar (ej. Joule, inducción, bombardeo electrónico, ...) dentro de una cámara de vacío o bajo atmósfera inerte a muy baja presión. Las moléculas de vapor se propagan hasta encontrar el substrato (vidrio) donde se condensan.

- Pulverización catódica (Sputtering). El vapor es obtenido por bombardeo de partículas de un gas, parcialmente ionizado, sobre el cátodo del material a depositar, arrancando átomos de éste que se proyectan sobre el substrato.
La descarga de los iones positivos del gas produce electrodos secundarios que vuelven a entrar en colisión con los átomos del gas ionizado de nuevo, dando continuidad al ciclo.

- Pulverización catódica con magnetrón. Con el mismo principio de la anterior su particularidad (Fig. 3) es la superposición sobre el cátodo de un campo magnético que permite confinar próximos a la diana a los electrodos secundarios, aumentando así el rendimiento de la reacción de ionización del gas. Se incrementa así la velocidad de depósito. Es, sin duda, el sistema más utilizado actualmente.

- Pulverización reactiva. Se incorpora al anterior y permite los depósitos de compuestos di-atómicos estables por reacción del cátodo con un gas previamente elegido. (Se forman así las capas de óxidos, carburos, nitruros, etc.)

Con la tecnología descrita, utilizada por los fabricantes de vidrio plano, se abre un campo espectacular a la innovación en la construcción. El número de productos disponibles es muy elevado y continuamente se fabrican otros nuevos en función de la demanda. 


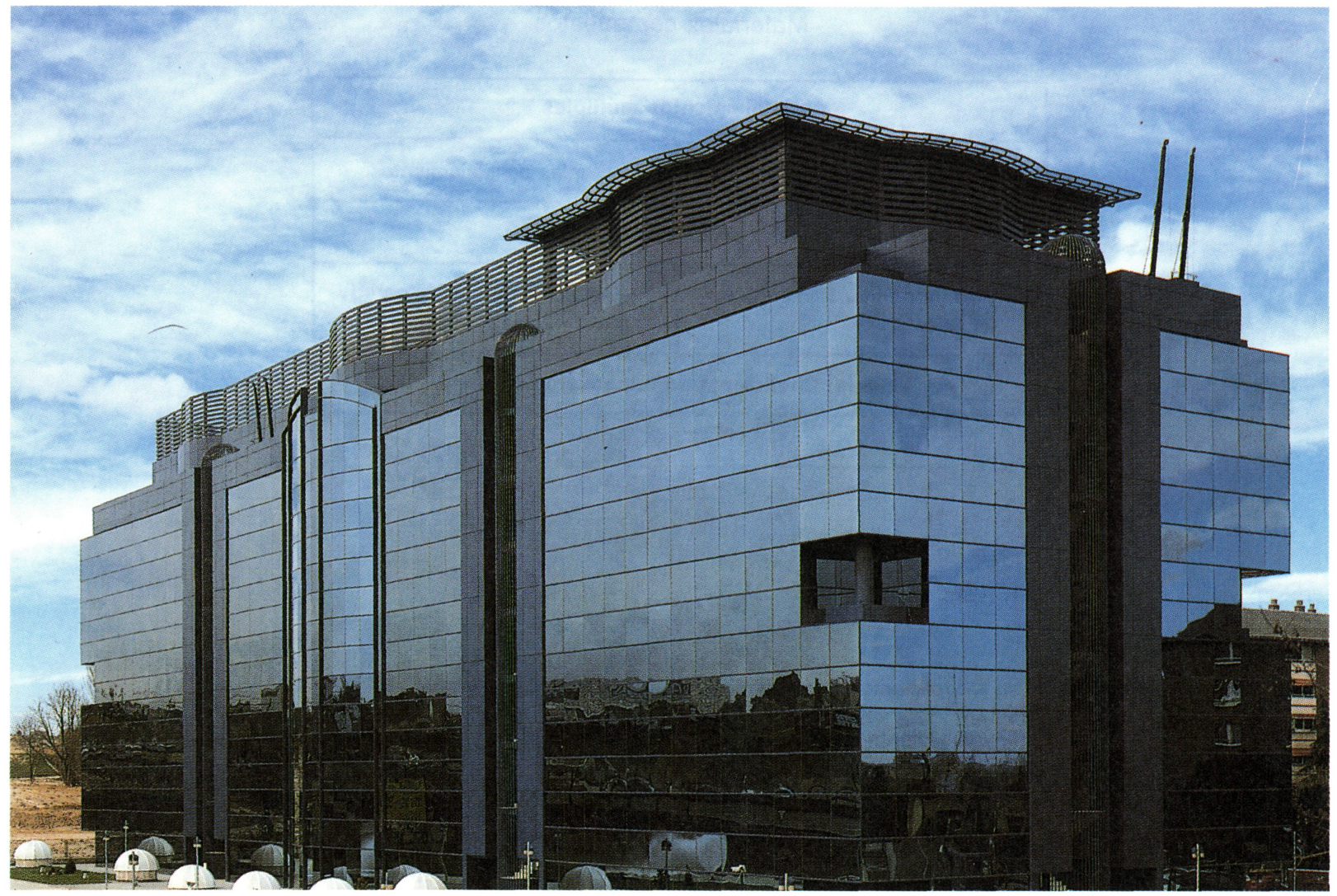

En general, los productos comercializados consisten en una o varias capas finas de metales $(\mathrm{Au}, \mathrm{Ag}, \mathrm{Cr}$, $\mathrm{Ti}$, $\mathrm{Zn}, \mathrm{Sn}, \mathrm{Cu}, \mathrm{Ac}$. inox. etc.) y/u óxidos metálicos, depositados sobre un vidrio (substrato) incoloro o de color. Se puede disponer así de vidrio con una elevada gama de colores y variantes en las $T_{L}, T_{E}, R_{L}, F_{S}, E, \ldots$

Solamente en el catálogo de los "COOL-LITE" existen 14 colores diferentes, con 46 referencias diferenciadas por el aspecto y por sus características luminosas y energéticas.

En el propio Grupo SAINT GOBAIN se sigue un importante programa de investigación para la obtención de multicapas que tengan un buen compromiso entre la transmisión luminosa deseada, un factor solar bajo y la coloración y reflexión exterior elegida.

Una particularidad de esta familia de productos son los dotados de capas de baja emisividad (Low-E). Son multiplacas tipo "PLANITHERM" (Ox. de estaño/plata/ox. de estaño) con un coef. de emisividad $(E \sim 0,1)$ y una Transmisión Luminosa elevada $\left(T_{L} \sim 80 \%\right)$ en vidrio monolítico de e=4 $\mathrm{mm}$.
Son productos dirigidos a limitar las pérdidas energéticas por los acristalamientos.

Como resumen, con esta importante familia de nuevos vidrios funcionales, la elección del vidrio soporte, la capa y la composición o producto final de montaje en el edificio, se pueden conseguir:

- VIDRIOS DE COLOR ANTISOLARES. Con fuerte reflexión en el visible y en el IR solar (Baja Transmisión Luminosa y Factor Solar).

- VIDRIOS NEUTROS ANTISOLARES. Bajas reflexión y absorción en el visible (INCOLOROS) y alta reflexión en el IR solar (bajo FS).

- VIDRIOS NEUTROS NO-EMISIVOS (Low-E). Permiten el paso de la energía solar (luz y calor) y reflejan el IR lejano. Facilitan las aportaciones solares y aumentan el aislamiento.

Y los compromisos y combinaciones entre todos ellos, que permiten resolver la mayor parte de las exigencias de estética, confort y economías de energía en la edificación moderna. 
TABLA VII

Materiales compuestos

\begin{tabular}{|c|c|c|}
\hline \multicolumn{3}{|c|}{ Acristalamientos múltiples } \\
\hline & bles acristalamientos & Triples acristalamientos \\
\hline \multicolumn{3}{|c|}{ Función: Aislamiento térmico } \\
\hline & $\begin{array}{l}\text { ninución de transmisión } \\
\text { :alor }\end{array}$ & $\begin{array}{l}\text { Reducción de efecto "pared } \\
\text { fría" }\end{array}$ \\
\hline \multicolumn{3}{|c|}{ Medida: Coeficiente de transmisión de calor } \\
\hline \multicolumn{2}{|c|}{$K=\frac{1}{\frac{1}{n_{e}} \cdot \frac{\Sigma_{c}}{\lambda} \cdot \frac{1}{n_{d}}+\frac{1}{n_{i}}}$} & \\
\hline \multicolumn{3}{|c|}{$\mathrm{K}\left(\mathrm{W} / \mathrm{m}^{2} \cdot{ }^{\circ} \mathrm{C}\right)$} \\
\hline \multicolumn{3}{|c|}{ he $=$ coeficiente de intercambio superficial externo } \\
\hline \multicolumn{3}{|c|}{$h_{1}=$ coeficiente de intercambio superficial interno } \\
\hline \multicolumn{3}{|c|}{$e=$ espesor de cada vidrio } \\
\hline \multicolumn{3}{|c|}{$\lambda=$ coeficiente de conductibilidad térmica del vidrio } \\
\hline$h_{0}=$ & oef. de intercambio (convec & n) del interior del acrist. \\
\hline
\end{tabular}

\section{- Capas por sol-gel}

Es una vía que, aunque poco utilizada aún a nivel industrial, tiene un importante futuro para los depósitos o capas de propiedades selectivas. Conceptualmente y a nivel de Laboratorio tiene pocas limitaciones en cuanto a la naturaleza de las capas o la pureza de éstas.

Esencialmente, aunque existen varios procesos diferentes, consiste en partir de una solución -Sol-que contiene sílice coloidal en suspensión y los demás componentes de la capa en disolución. Inmersión del vidrio a recubrir y extracción a velocidad controlada para ajustar el espesor de la capa. Polimerización. Condensación. Evaporización para formar el Gel. Secado lento y tratamiento térmico para formar la capa vitrea.

Pueden realizarse, por esta técnica, películas de propiedades ópticas muy selectivas (Reflectantes, Antirreflectantes, de Color, Foto-Electrocrómicas, etc., etc.), películas de protección, conductoras, magnéticas, etc., etc.

\section{PRODUCTOS COMPUESTOS. VIDRIOS Y OTROS MATERIALES}

El vidrio se asocia bien con otros materiales (plásticos/metales/etc.) para dar lugar a productos compuestos con nuevas propiedades.

Las asociaciones más frecuentes en vidrio plano son:

- Vidrio/vidrio con diversos elementos de separación/unión/sellado.

- Vidrio/XXX/vidrio/... formando productos estratificados. Dando lugar a productos vidrieros muy conocidos y extendidos en el mercado.

- Los acristalamientos múltiples (principalmente, el doble acristalamiento del que se venden en Europa más de 50 millones de $\mathrm{m}^{2}$ por año), dedicados al aislamiento térmico.

\section{- Los vidrios de seguridad por ensamblados de capas} sucesivas vidrio/plástico, 
TABLA VIII

Aislamiento térmico de los acristalamientos

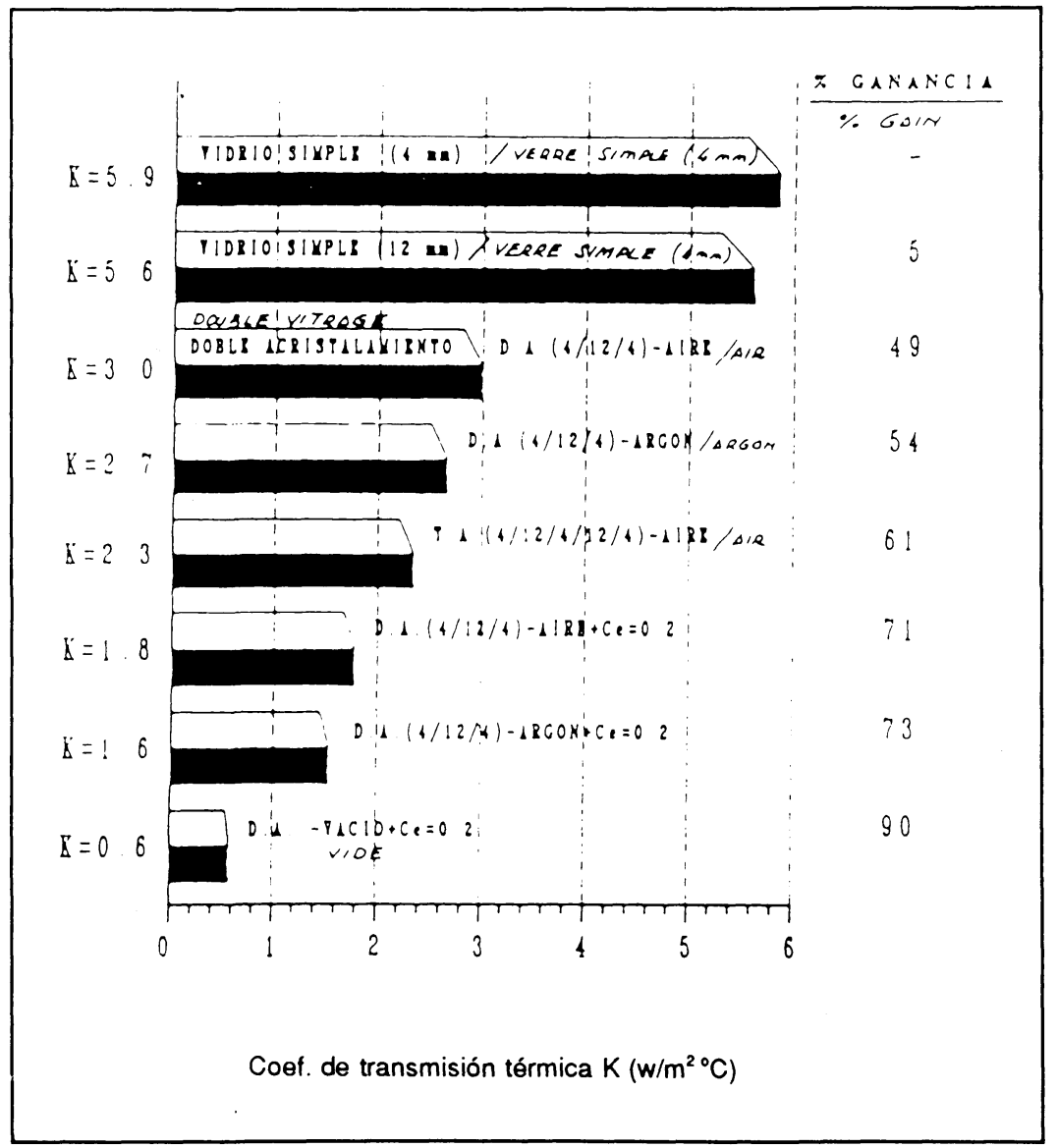

y otros nuevos vidrios (aún en vías de desarrollo industrial) con propiedades muy especiales: vidrios con cristales liquidos; V. con películas holográficas, etc.

Habitualmente, se combinan en los acristalamientos los vidrios de color y las capas dentro de estos vidrios compuestos para dar lugar a productos muy completos que responden a las tres exigencias básicas de es. tética, confort y seguridad.

\section{- Acristalamientos múltiples}

Son productos vidrieros de uso muy extendido y suficientemente conocidos en sus aplicaciones en la construcción. El proceso de fabricación, sus componentes, su utilización, ... está perfectamente descrita en la numerosa bibliografía existente (veáse MANUAL del VI. DRIO del CITAV). Sólamente se recordará, a continuación, su función principal y se hará una referencia a los desarrollos actuales de estos productos.

Su función esencial es el aislamiento térmico, que se manifiesta por la resistencia del acristalamiento a transmitir el calor de una pared a la opuesta (V. tabla
VII). El coef. de transmisión de calor (K) depende de los espesores de los vidrios, de la cámara de separación de éstos y de los intercambios caloríficos en las distintas paredes.

Como resultado práctico de medidas, bajo condiciones pre-establecidas, se obtiene:

- V. monolítico: $\mathrm{K} 5,7 \mathrm{~W} / \mathrm{m}^{2}{ }^{\circ} \mathrm{C}$.

- D.A. (4/12/4): K $3,0 \mathrm{~W} / \mathrm{m}^{2}{ }^{\circ} \mathrm{C}$.

La evolución de estos productos está orientada a la reducción del coef. $\mathrm{K}$ (a la mejora del aislamiento térmico). Dos vias son preferentemente seguidas:

- Sustitución del aire de la cámara interior por otros gases con:

- Menor conducción térmica.

- Temperaturas de condensación más bajas.

- Espectros de absorción en el IR. 


\begin{tabular}{|c|c|c|}
\hline Denominación & $\begin{array}{c}\text { Composición y espesores de las } \\
\text { lunas } \\
(\mathrm{mm})\end{array}$ & $\begin{array}{c}\text { Dimensiones de fabricación } \\
\text { (cm) }\end{array}$ \\
\hline Seguridad simple $A_{1}$ & $3+3$ & $312 \times 201$ \\
\hline Seguridad fuerte $A_{2}$ & $\begin{array}{c}4+4 \\
5+5 \\
6+6\end{array}$ & $\begin{array}{l}420 \times 240 \\
420 \times 240 \\
750 \times 240\end{array}$ \\
\hline
\end{tabular}

TABLA X

\begin{tabular}{|c|c|c|c|}
\hline Nivel de energía & Tipo de arma & $\begin{array}{c}\text { Espesor STADIP } \\
(\mathrm{mm})\end{array}$ & $\begin{array}{c}\text { N. }{ }^{\circ} \text { homologación } \\
\text { D.G.S.E. }\end{array}$ \\
\hline \multirow{2}{*}{$C_{1}$} & $\begin{array}{l}\text { Pistola STAR } 9 \mathrm{~mm} \\
\text { Parabellum }\end{array}$ & \multirow{2}{*}{$26 / 28$} & \multirow{2}{*}{00768} \\
\hline & Subfusil STARLING & & \\
\hline $\mathrm{C}_{2}$ & $\begin{array}{l}\text { Revolver ASTRA } \\
357 \text { MAGNUM }\end{array}$ & $26 / 28$ & 00768 \\
\hline $\mathrm{C}_{3}$ & $\begin{array}{l}\text { Revolver ASTRA } \\
44 \text { MAGNUM }\end{array}$ & $43 / 45$ & 03230 \\
\hline \multirow{3}{*}{$\mathrm{C}_{4}$} & $\begin{array}{l}\text { Escopeta REMINGTON } \\
\text { Calibre } 12 \text { postas impactos } \\
\text { separados }\end{array}$ & $59 / 61$ & 03230 \\
\hline & $\begin{array}{l}\text { Escopeta REMINGTON } \\
\text { Calibre } 12 \text { postas impactos } \\
\text { superpuestos }\end{array}$ & $59 / 61$ & 03230 \\
\hline & $\begin{array}{l}\text { Escopeta REMINGTON } \\
\text { Calibre } 12 \text { bala de plomo } \\
\text { Brenneke }\end{array}$ & $59 / 61$ & 03230 \\
\hline $\mathrm{C}_{5}$ & Fusil CETME Cal. 7.62 & $59 / 61$ & 03230 \\
\hline
\end{tabular}

- Capas de baja emisividad que actúen como barrera a la radiación IR.

Con la combinación de ambas soluciones puede llegarse a acristalamientos con una ganancia en el aislamiento térmico superior al $70 \%$. En la tabla VIII se expresan los valores del $\mathrm{K}$ para diversos tipos de acristalamientos.

$(\mathrm{Ce}=0,2$ significa que uno de los vidrios tiene en su cara interior una capa de emisividad $E=0,2$ ).

En estos productos se integran también otras funciones:
- Control solar.

Fabricándolos con vidrios/capas adecuados a este fin.

- Aislamiento acústico.

Eligiendo los espesores de las láminas de vidrio y de la cámara de aire se puede llegar a atenuaciones acústicas de los ruidos de circulación del órden de $35 \mathrm{~dB}(\dot{\mathbf{A}})$.

\section{- Seguridad.}

Colocando en su exterior vidrios estratificados o laminares tipo "STADIP". 
TABLA XI

Características acústicas de los productos vítreos

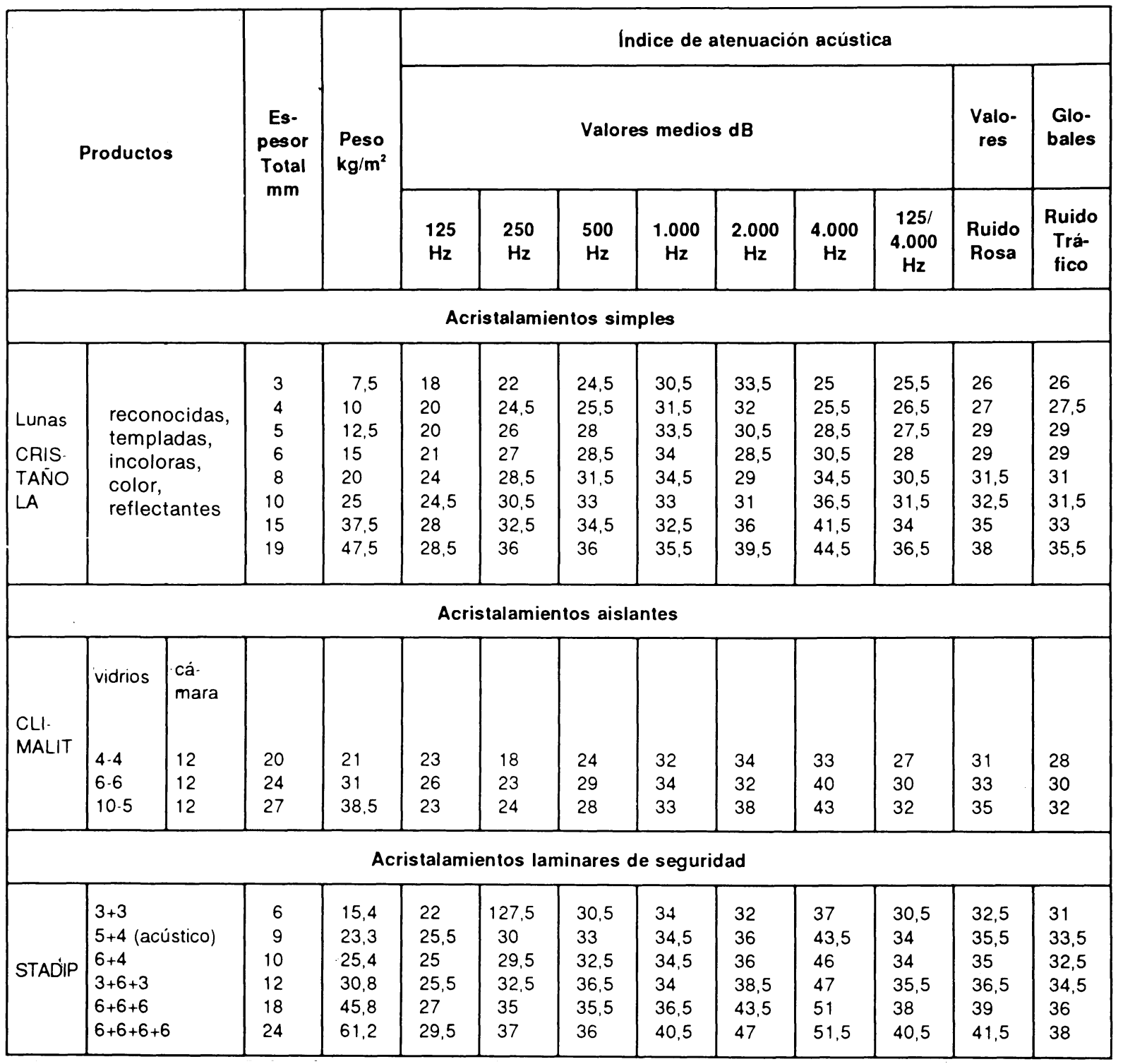

Atención: Estos valores están referidos al vidrio. En ningún caso indican el aislamiento acústico del conjunto vidrio + carpintería.

\section{- Vidrios estratificados}

Son vidrios compuestos, formando un solo bloque, de dos o más láminas de vidrio intimamente unidas en toda su superficie por uno o varios films intercalarios. Los films se eligen teniendo en cuenta su plasticidad, resistencia, elasticidad, aherencia y alta calidad óptica después de un tratamiento térmico. En general son de Butyral de Polivinilo (PVB). Los vidrios e intercalarios una vez ensamblados se tratan en caliente bajo presión elevada para obtener un material compacto (un “COMPOSITE") de excelentes propiedades.

Son principalmente, vidrios de seguridad en diversos grados:
- Reducen los riesgos de heridas cortantes y accidentes por penetración.

Resisten bien los impactos y cuando rompen, el vidrio queda adherido al plástico evitando riesgos de caídas o desprendimientos de trozos cortantes.

- Protegen de agresiones voluntarias, vandalismo, robo, disturbios...

- Puede formarse (en función del número de capas y espesor total) un blindaje contra la acción de armas de fuego.

(En las tablas IX y X se dan las composiciones de algunos productos comerciales). 


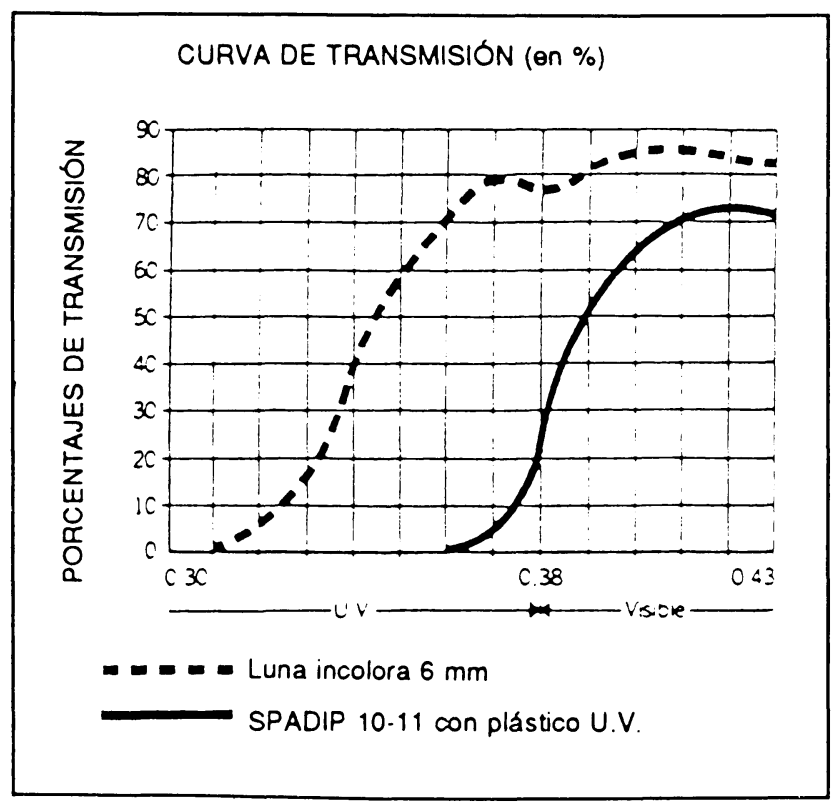

Fig. 4

Además de la función principal de seguridad puede ampliarse su funcionalidad a campos como:

- Protección de la radiación solar (en combinación con capas reflectantes).

- Filtración de las radiaciones UV, desplazando el "cut-off" del UV solar hasta el dominio del visible (por el efecto unido del vidrio y de un PVB anti UV) (Fig. 4).

- Protección acústica. Basándose en la "ley de masas" la atenuación acústica de estos productos puede ser muy elevada.

Se resumen en la tabla XI las características de atenuación acústica, a las distintas frecuencias, de diversos productos de vidrio mencionados hasta aquí.

\section{- Otros vidrios compuestos}

Existen o están en vía de desarrollo industrial otras numerosas aplicaciones del vidrio combinado con otros materiales. Por su interés para la construcción, aunque se trata de productos especiales de uso limitado, se citan a continuación algunos de éstos:

\section{- Vidrios para-llamas}

Que impiden el paso de las llamas durante un cierto tiempo. El vidrio es incombustible pero puede producirse su rotura por choque térmico. Se utilizan vidrios armados c.on mallas metálicas, para mantener la cohesión y asegurar la estanquidad a las llamas durante un cierto tiempo.

\section{- Vidrios corta.fuegos}

Además de impedir el paso de las llamas, limitan la transmisión del calor al otro lado de la pared (evitando el incendio de materiales inflamables próximos: muebles, cortinas, etc.).

Un producto, ejemplo de esta gama, consiste en un doble acristalamiento con vidrios templados y el espacio entre ambos lleno de un gel acuoso, perfectamente transparente e incoloro en condiciones normales. En caso de incendio, el gel reacciona al calor, se transforma en una capa aislante y se vuelve progresivamente opaco a la radiación.

- Productos tipo "CONTRAFLAM" pueden mantenerse durante 60 ó 90 minutos con un gradiente térmico entre ambas caras de casi $800^{\circ} \mathrm{C}$. 


\section{ELECTROCROMISMO}

Capas activas que cambian su transmisión luminosa al someterlas a una diferencia de potencial eléctrico.

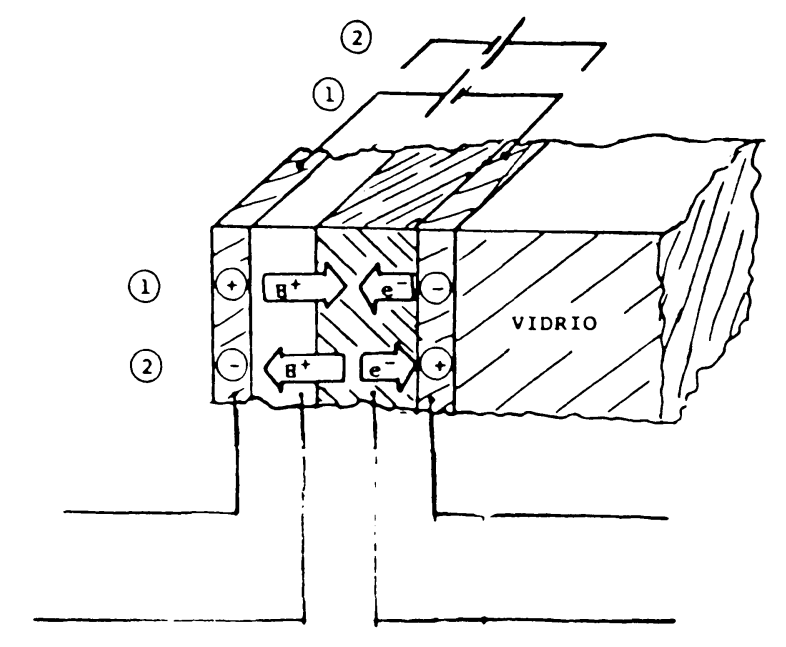

(1) Paso de iones $\mathrm{H}^{+}$y e a la capa $\mathrm{WO}_{3}$ $\theta^{*}+W^{+5} \rightarrow W^{+5} \rightarrow$ oscurecimiento

Inversión del proceso $W^{+5} \rightarrow W^{+6}+\theta \rightarrow$ transparencia

\section{- Vidrios - policarbonatos}

Los estratificados de vidrios y policarbonatos tienen una gran resistencia mecánica y a los impactos de alta energía. Se utilizan normalmente en blindajes.

\section{VIDRIOS CON PROPIEDADES VARIABLES}

Las investigaciones más recientes en el campo del vidrio plano se dirigen a la obtención de acristalamientos con posibilidades, técnicas y de coste, de ser industrializados, con propiedades que pueden ser alteradas en el acristalamiento instalado, ya sea a voluntad (p. ej. "acristalamientos electrocomandados"), ya sea como reacción a las condiciones exteriores (los llamados "acristalamientos inteligentes"). De unos y otros se citan algunos de los más representativos:

\section{- Vidrios termocrómicos}

Son vidrios con ciertas capas que cambian sus propiedades ópticas por la acción del calor. Tienen esta propiedad las capas de óxido de vanadio $\left(\mathrm{VO}_{2}\right)$ que sufre una transición semiconductor-metal a $68^{\circ} \mathrm{C}$ (dopando el $\mathrm{VO}_{2}$ puede llegarse a los $25^{\circ} \mathrm{C}$ ).

\section{- Vidrios fotocrómicos}

Los vidrios que contienen agentes fotocrómicos cambian su transmisión luminosa (se produce el oscurecimiento) por el efecto de la irradiación. Este efecto es reversible volviendo a su estado anterior cuando desaparece el estímulo.

En general, es un efecto de masa en vidrios que contienen tierras raras, haluros de plata, halogenuros de cobre y cadmio, etc.

Son muy empleados en óptica. Su extensión a la construcción ha estado limitada, hasta ahora, por el elevado precio de sus componentes.

\section{- Vidrios electrocrómicos}

A diferencia de los anteriores, en este tipo de vidrios sus propiedades ópticas son variadas a voluntad por el efecto de un potencial eléctrico.

El mecanismo de estas capas (Fig. 5) es el cambio de valencia de ciertos óxidos semiconductores $\left(\mathrm{WO}_{3}\right.$; $\mathrm{V}_{2} \mathrm{O}_{5} ; \mathrm{MoO}_{3}$; etc.), ocasionando bandas de transición en el visible. 


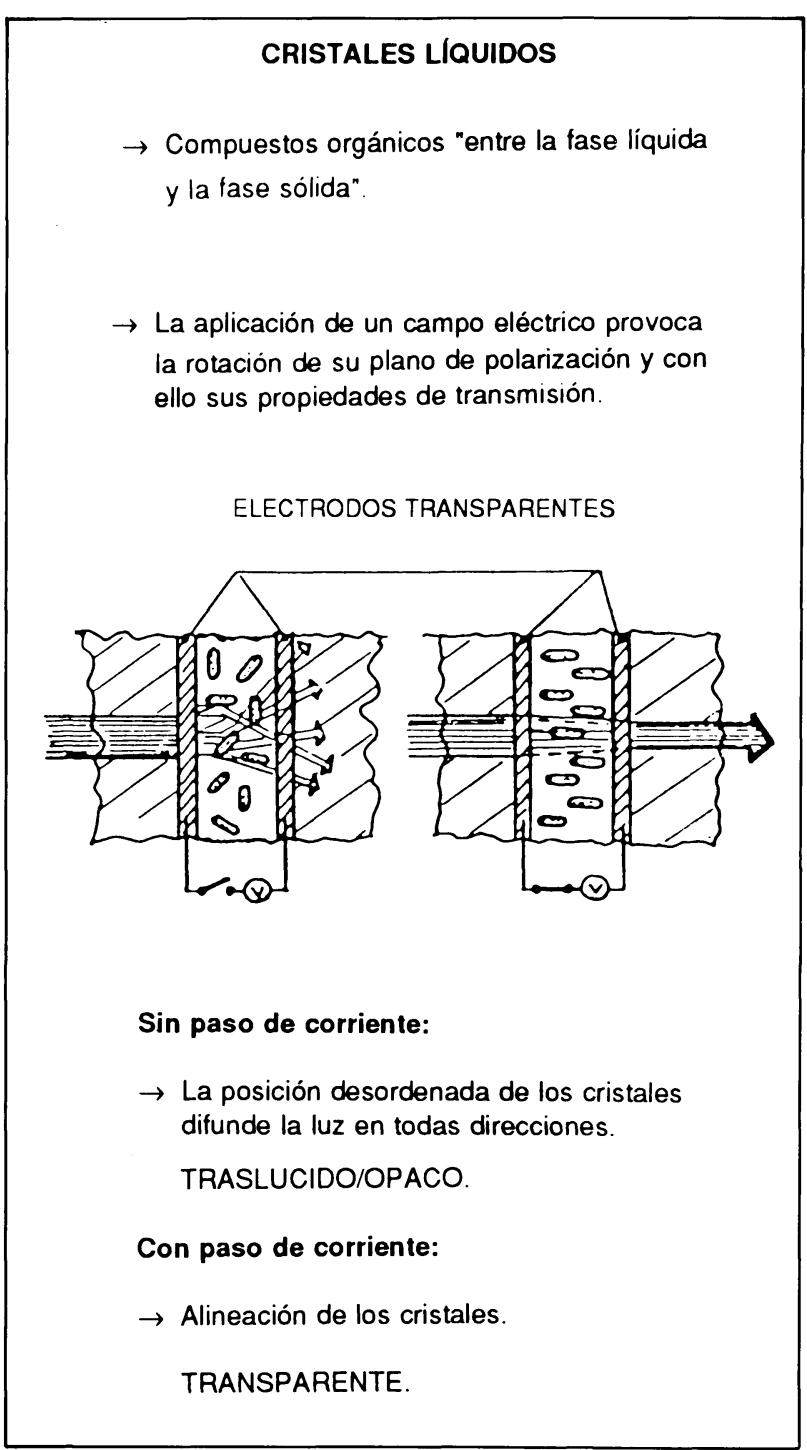

Fig. 6

Dicho cambio de valencia se produce inyectando simultáneamente electrones y cationes por ambos lados de la capa del compuesto electrocrómico.

El conjunto está formado por el apilado de varias capas sobre un vidrio $\left(\mathrm{SnO}_{2}\right.$-conductora/ $\mathrm{WO}_{3}$-electrocrómica/electrólito/ $\mathrm{SnO}_{2}$-conductora).

El tiempo de reacción es muy pequeño (segundos), cambiando la transmisión luminosa desde un $80 \%$ (máx.) hasta un $5 \%$ (mín.) de la luz incidente.

La reacción es reversible, mediante la aplicación de un potencial eléctrico de sentido contrario al inicial.

Están ya desarrollados diferentes tipos, aunque sólo en dimensiones reducidas. Múltiples investigaciones en curso permiten asegurar que pronto serán productos utilizados en acristalamientos en la construcción.

\section{- Vidrios con cristales líquidos}

Los cristales líquidos son estados intermediarios entre la fase líquida y la fase sólida que presentan ciertos compuestos orgánicos (Fig. 6). Tienen, como variaciones, varias arquitecturas moleculares. En la fase "Nemática" poseen un orden orientacional. En la "Colestérica" una torsión. Estos dos estados presentan una transmisión luminosa diferente.

La aplicación de un campo eléctrico, bajo cierta frecuencia e intensidad, puede hacer girar dichas moléculas y cambiar el espectro de transmisión (color) o solamente la difusión de la luz (la transparencia o la opacidad de los cristales).

Una aplicación, ya en el mercado, es el "PRIVALITE". Los cristales líquidos están contenidos en un film con sus superficies recubiertas de capas conductoras transparentes. Este film se sitúa dentro de un vidrio estratificado (dos placas) ensamblado con PVB.

Cuando se establece un campo eléctrico entre las dos superficies conductoras, los cristales se ordenan y el film, anteriormente translúcido (opalino), se vuelve transparente. Este cambio es totalmente reversible.

\section{- Vidrios con películas holográficas}

Son vidrios estratificados que, además del intercalario de unión (PVB), llevan en su interior un film fotográfico sobre el que se han impresionado ondas coherentes, producidas por una radiación monocromática láser, provenientes de diferentes direcciones (Fig. 7).

Pueden producirse así, sobre la película, interferencias constructivas o destructivas entre las 2 ondas, en función del desfase entre ellas, debido a la diferencia de caminos recorridos. Si el objeto reproducido es una superficie plana y el soporte es transparente se produce un holograma con superposición de dos ondas planas.

Esta estructura de capas interferenciales puede reflejar determinadas longitudes de onda y permitir el paso de otras en función del ángulo de incidencia.

Aunque son productos cuya aplicación industrial está aún en fase de investigación, presentan un gran interés para la construcción. Una de sus aplicaciones puede ser la obtención de capas filtrantes selectivas (curva de la Fig. 7) que reflejen el IR y transmitan el visible sin dispersión cromática. También podría dar lugar a acristalamientos de colores cambiantes en función de la incidencia de la luz.

Actualmente, comienzan a difundirse en el campo de la información y la publicidad (imágenes en tres dimensiones). 


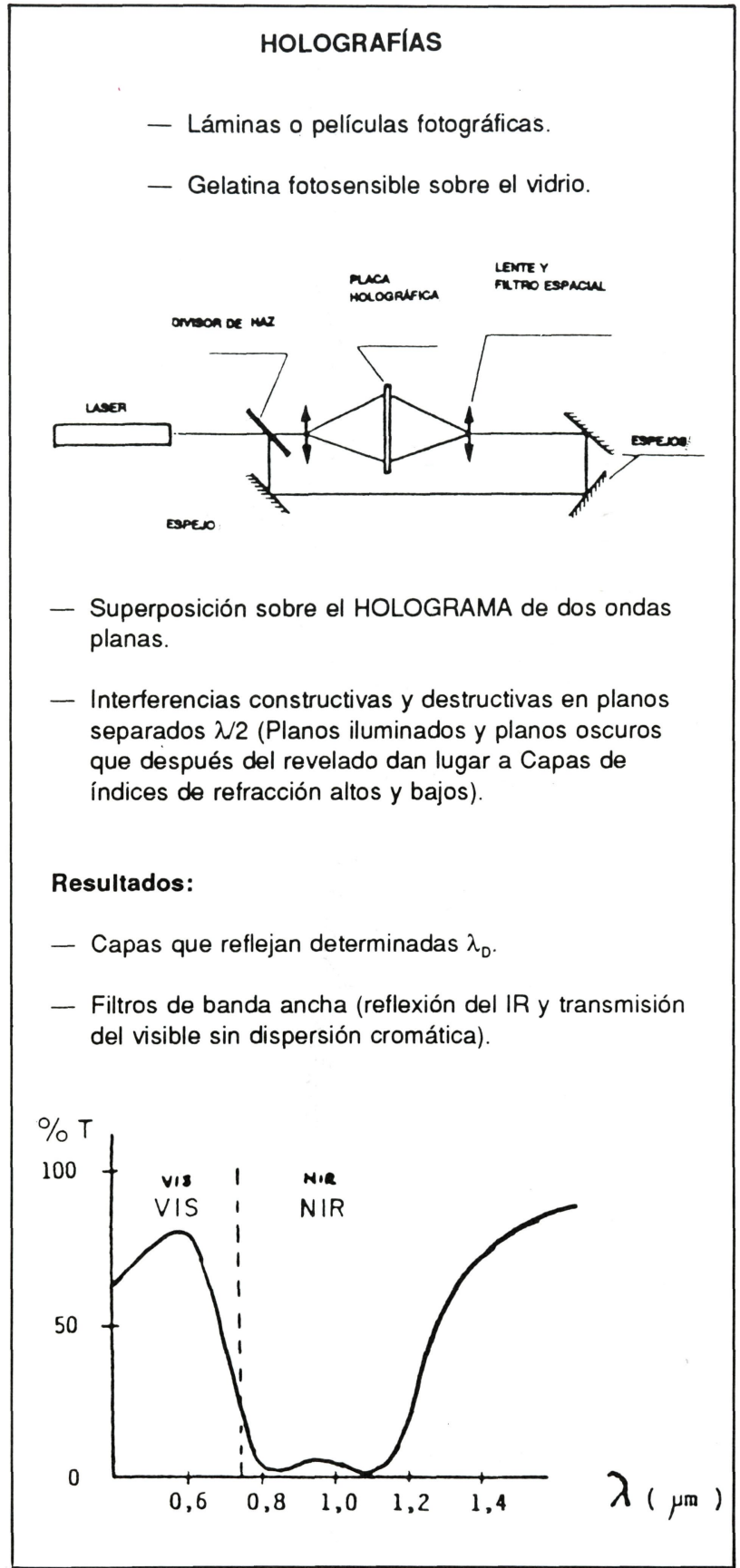

Fig. 7

\section{VIDRIOS LAMINADOS O IMPRESOS}

Forman parte de la gama más antigua dentro de la familia del vidrio plano actual. Son sobradamente conocidos en la construcción por su extendida utilización durante muchos años (cierres de naves, mamparas interiores de separación, luminarias; puertas, etc., etc.)

Se producen por colada y laminación de un vidrio fundido entre dos rodillos metálicos, de los que uno está grabado, imprimiendo un dibujo en relieve sobre una de las caras del vidrio. El producto final es una hoja de vidrio plano que produce una dispersión de la luz

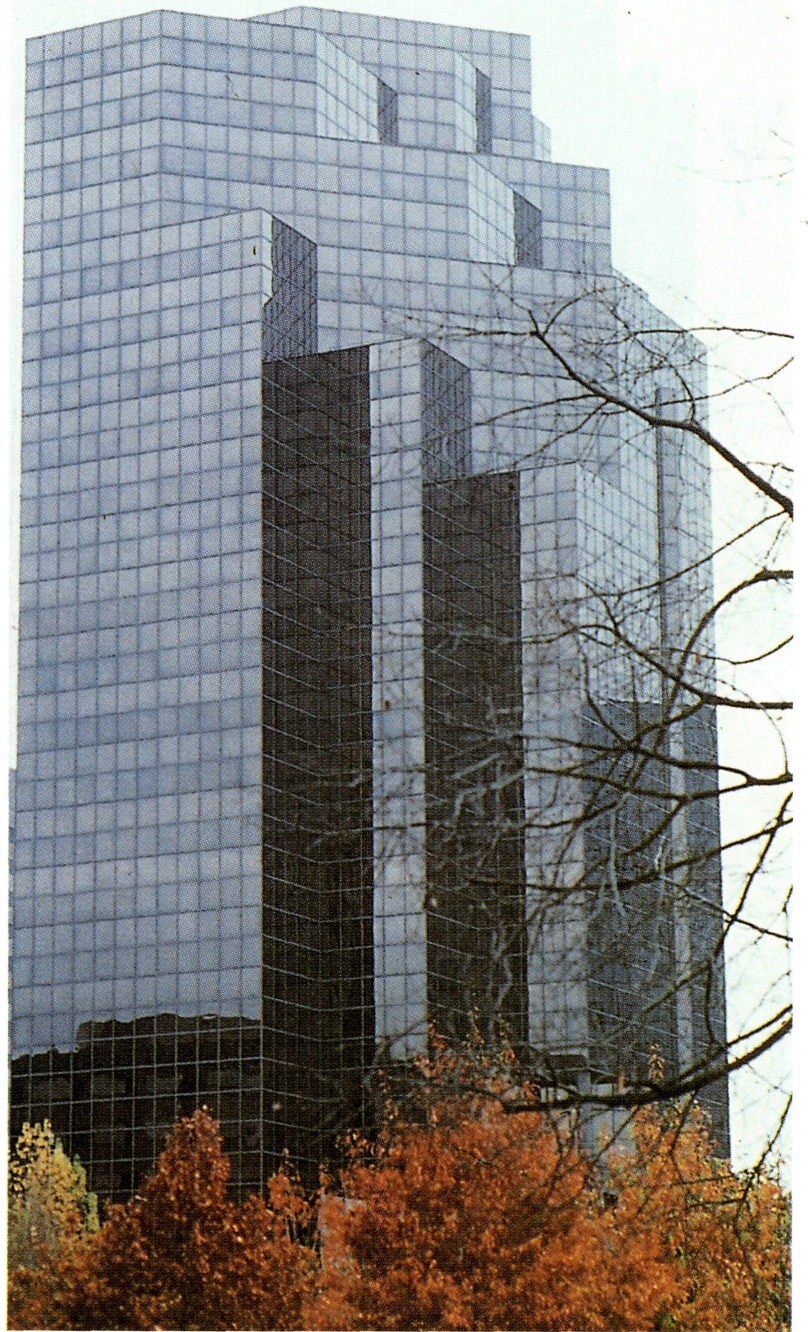

(producto translúcido) y con una transmisión luminosa del 50 al $90 \%$ según el color. Sus restantes propiedades físicas son similares al resto de productos de vidrio plano.

Dos variantes interesantes en la construcción son:

- VIDRIOS IMPRESOS TEMPLADOS. Con temple físico, para aumentar su resistencia mecánica y al choque térmico.

- VIDRIOS IMPRESOS ARMADOS. Llevan incorporada en su masa una malla metálica soldada, de retícula cuadrada, introducida durante la laminación. Además de impedir la penetración y reducir el riesgo de rotura y desprendimiento de trozos, son utilizados también como productos para-llamas.

Estos vidrios también pueden ensamblarse entre sí o con otros vidrios planos de caras lisas formando dobles acristalamientos o estratificados. Además de las utilizaciones mencionadas, encuentran su máximo empleo por su aspecto decorativo y la difusión de la luz evitando la visión directa a través de ellos. 